\title{
Rumos da formação de professores para a Educação Ambiental *
}

\section{Towards teachers preparation for Environmental Education}

\author{
Giana Raquel Rosa Gouvêa **
}

\begin{abstract}
RESUMO
O presente trabalho tem como objetivo refletir sobre a importância do investimento humano e conceitual na inserção da educação ambiental no processo de formação de professores. Trata-se de um estudo de caso, de natureza empírica, realizado em dois centros universitários localizados em Lorena e Barra Mansa, que atuam significativamente, na formação de professores da região. No processo de coleta de dados, foram atendidas as premissas que norteiam um estudo de caso, segundo yIN (2001), bem como fontes de evidências variadas. Os dados receberam tratamento quantitativo e qualitativo, dependendo na natureza da evidência. Nesse sentido, o estudo revela que, embora os professorandos que participaram da pesquisa, tivessem pouca ou nenhuma noção da importância do trabalho de educação ambiental, tal situação pode ser alterada, inclusive no tocante às discussões que ocorrem no ambiente universitário e no replanejamento de planos e projetos pedagógicos dos cursos vocacionados para a formação de professores. Desta forma, a reflexão constante sobre "o que preciso saber para ensinar?”, “por que e para que ensinar?” caminha juntamente com o "como ensinar?" na construção de um saber ambiental embasado pelo compromisso social e humano necessário à formação dos professores e à superação da dispedagogia ambiental.

Palavras-chave: educação ambiental; formação de professores; dispedagogia ambiental.
\end{abstract}

* Este trabalho representa o resumo da dissertação de mestrado defendida em 2004, na Universidade Federal do Rio de Janeiro, sob orientação da Profa. Dra. Speranza França da Mata.

** Professora do Centro Universitário Salesiano de São Paulo - U.E. Lorena. E-mail: gianagouvea@gmail.com 
GOUVÊA, G. R. R. Rumos da formação de professores para a...

\begin{abstract}
The objective of this work is to reflect about the importance of human and conceptual investment in the insertion of the Environmental Education in the process of teacher training. This is a Case Study, empirical, carried out in two University Centers (Lorena and Barra Mansa) that are meaningfully working with teacher training. In the data collection process, the work followed the Case Study methodology according to Yin (2001), as to sources and varied evidences. The data received quality and quantity treatment, depending on the nature of evidence. In this sense, the study shows that, although teachers who carried out the research had a few or no notion of the importance of the Environmental Education, they know that such situation can be improved, even in the discussions at the University and in the replanning of pedagogical projects in the courses for teacher training. In this sense, the usual questions about "what do I need to know to teach?”, "why and what to teach?”, come together with "how to teach?” in the building of a environmental knowledge based on the social and human commitment necessary to teacher training in order to surpass the environmental dispedagogy.

Key-words: environmental education; teacher training; environmental dispedagogy.
\end{abstract}

Iniciando a caminhada: educação ambiental e formação de professores

Desde os anos 70, estamos envolvidos em transformações sem precedentes nas esferas econômica, política, sociocultural e ambiental. Essas transformações, configuradas pela reestruturação produtiva do processo capitalista, encerradas sob os ditames do pensamento neoliberal e do processo de globalização, desestruturam conquistas sociais importantes e tornam ainda mais evidentes quão frágeis são a economia, a política e a organização social da maioria dos estados nacionais do Planeta. Assim, afirma Boff (1999), aqueles que detêm o monopólio do ter, poder e saber, controlam não apenas os mercados, mas também todas as estruturas que garantem a manutenção e a disseminação das ideologias dominantes. Nesse cenário, a educação e o ambiente obviamente não escapam a este tipo de lógica. 
Na forma de apropriação do ambiente e de seus recursos, com o advento da globalização e neoliberalismo, a humanidade parece assistir passiva o acometimento de danos irreversíveis ao Planeta, pois, de acordo com Leff (2002), a acumulação de capital e as formas de consumo, presentes na sociedade atual, vêm esgotando os recursos naturais, causando, entre outros problemas, a degradação dos solos e desestruturando a capacidade natural de regeneração dos ecossistemas.

Durante certo tempo, a educação ambiental restringiu-se a cumprir seu papel na perspectiva preservacionista. No entanto, instada a transitar na complexa tessitura de conhecimentos políticos, éticos, econômicos, culturais e outros, impôs-se transcender ao reducionismo das práticas esporádicas, relacionadas a datas comemorativas, a desenvolvimento de mini-projetos específicos, a cuidados com hortas e jardins, ao cultivo de plantas medicinais, à reciclagem de lixo e materiais, ou a anúncios e denúncias das conseqüências das “ecocatástrofes”. Tais práticas não produziram, efetivamente, alterações nos padrões de consumo e na maneira de viver da sociedade globalizada. Mais do que isso, as pessoas que assim praticavam educação ambiental foram associadas a causas e movimentos que antes lograram rótulos pejorativos como “ecochatos”, ou “exterminadores do futuro” pois na verdade, não desenvolviam consciência, não transformavam hábitos e atitudes e não educavam; e, se não educavam, não refletiam; e, se não refletiam, não transformavam.

Nos dizeres de Leff (2001), a educação ambiental deveria tentar articular, subjetivamente, o educando ao conhecimento, bem como suas formas de produção, a descobrir os sentidos e sabores do saber, a desenvolver, mais que o pensamento crítico, um pensamento reflexivo e prospectivo capaz de combater condutas automatizadas, o pragmatismo e o utilitarismo tão presentes na sociedade globalizada moderna.

Para cumprir este papel, a educação ambiental deve envolver como objeto próprio, o confronto com as estratégias de desenvolvimento e do processo de globalização, bem como comportar, nesta missão, a dimensão da cidadania, da ética e da justiça. Nesse sentido, trabalhar com educação ambiental significa reunir não apenas a capacidade de superar desafios que nos são cotidianamente apresentados no mundo moderno, como também esperar que seus militantes/defensores se reconheçam e ajam como cidadãos, para também inspirar a construção/garantia desse processo em seus educandos/aprendizes. No entanto, isso nem sempre é fácil de se conseguir, pois um profissional como o professor, marcado pela desvalorização, pelos baixos salários, pelo descaso com a sua formação, está muito mais preocupado em sobreviver do que em transformar. Nesse sentido, a valorização na formação do professor deve ser colocada em 
questão pois, no processo de valorização, as categorias política, técnica, profissional e humana tornam-se indissociáveis no plano profissional.

Rios (2001, p. 12) enfatiza que "não é qualquer um que pode ser professor" e nem qualquer professor que pode enfrentar os desafios presentes em nosso tempo. E foi pensando nessa premissa que esta pesquisa foi elaborada, com o intuito inicial de apenas inserir educação ambiental no processo de formação de professores. No entanto, no decorrer da pesquisa, outro problema mais complexo manifestou-se de forma mais premente: a caracterização da ação educativa ambiental como um processo que envolve a consciência da complexidade do processo de educação e as responsabilidades com o meio ambiente. Esse tipo de trabalho, apesar das demandas de sensibilização, encontra-se largamente difundido em nossa cultura e, diante de dados ambientais inquietantes, ainda não adquiriu o necessário espaço para efetiva discussão.

Assim, a presente pesquisa, mais que trabalhar educação ambiental na formação de professores, buscou resgatar a complexidade do processo de educar, refletindo sobre os caminhos que levam à compreensão de que "o mundo é do tamanho do conhecimento que temos dele. Alargar conhecimento, para fazer o mundo crescer, e apurar seu sabor, é tarefa de seres humanos. É tarefa, por excelência, de educadores” (RIOS, 2001, p. 24).

Nesse sentido vários questionamentos tornam-se aparentes: o educador considera as implicações ideológicas, políticas, econômicas e éticas do trabalho educativo que está realizando, na perspectiva ambiental? Estará construindo a prática da educação ambiental com a consciência da complexidade do processo educativo? Que rumos estará tomando a formação de professores em função da prática de educação ambiental?

Com essas preocupações em mente, fez-se uma reflexão inicial sobre a educação ambiental, resgatando o pensamento de Carvalho (2002) de que toda educação é ambiental, pois se assim não se proceder, perde-se o sentido de educar. Seguindo este posicionamento profissional, percebe-se que, a formação de professores deve orientar-se para contextos diferenciados e intrinsecamente interligados: social, político e pedagógico. Neste sentido, há necessidade de direcionar a formação de professores para estes assumirem a função de intelectuais transformadores (GIROUX, 2003) destinados a construir um saber ambiental (LEFF, 2001) sob o entendimento de que educar constitui um processo histórico e crítico. Nos dizeres de Freire (2003), exercer a relação dialética da docência e discência, numa práxis rica em criticidade, criatividade, problematizações e curiosidades. 


\section{Revendo percursos na prática educacional: dispedagogia e desedu- cação ambiental}

Desenvolver atividades socioambientais práticas no âmbito formal da sala de aula é um desafio para todos os professores. Assim, ao trabalhar com recursos como fotos, vídeos, músicas, histórias infantis e histórias em quadrinhos, garantiu-se a intencionalidade de possibilitar, aos professores e alunos, a análise crítica do recurso.

Esta análise crítica dos recursos didáticos faz-se necessária, pois os professores os utilizam indiscriminadamente, muitas vezes, para "preencher o tempo de aula”. Esta tendência reforça o que Giroux (2003) chama de cultura da inocência, difundindo através da mídia transformações culturais que tendem a alterar o comportamento humano e regular suas práticas sociais, tornando-se uma "força educacional substancial, senão a principal, na regulação de significados, de valores e de gostos, que estabelecem as normas e as convenções que oferecem e legitimam determinadas posições do sujeito” (p. 128).

Desta forma, é comum, principalmente no ensino fundamental e médio, professores utilizarem o recurso sem o acompanhamento crítico e pedagógico. Subjacente, os filmes, histórias, quadrinhos e músicas que enfatizam a desorganização familiar, a fantasia perfeita que chega a estagnar a imaginação, a normalização da violência, a solução de problemas em um passe de mágica, fazem os discentes ficarem seduzidos e vulneráveis aos valores e percepções expostos nessa forma de entretenimento.

A difusão da cultura da inocência torna impraticável uma das principais metas da educação (e da educação ambiental) que, segundo o próprio Giroux (1997, p. 203), é a de “criar condições para que os estudantes se fortaleçam e se constituam como indivíduos políticos”. Podemos estender esta afirmação tanto para estudantes como para profissionais, já que o sistema, hoje altamente reprodutor, raramente se preocupa com a formação crítica de seus professores, sendo que, nesse sentido, as instituições de formação de professores se apresentam como "prejudicialmente desprovidas de consciência social” (GIROUX, 1997, p. 196).

A falta de percepção e controle dos processos originados pela cultura da inocência nos recursos pedagógicos utilizados em sala de aula, esvazia estes recursos de significados e conteúdos, relegando-os à categoria de meros coadjuvantes no processo educativo.

Observa-se, assim, a dispedagogia ambiental como sendo uma das conseqüências do processo equivocado da formação de professores sem o 
compromisso com a ação emancipatória e com a ética da profis-sionalidade e da autonomia.

O conceito dispedagogia é utilizado por Fonseca (1995, p. 13-17) para designar os problemas de aprendizagem que são gerados pelas condições de ensino, ligadas ao professor e ao próprio ensino. Por transposição, dispedagogia ambiental pode ser aqui entendida como a carência de um projeto educacional que enfatize a importância dos aspectos político, social, cultural, teórico e prático da educação na construção da complexidade ambiental. As diretrizes dos sistemas educacionais, as condições de ensino e a formação pedagógica do professor incutem a naturalização de discursos e práticas ambientais desvinculados dos processos políticos, econômicos, sociais e culturais. A dispedagogia ambiental faz o professor acreditar que se ele desenvolve atividades pontuais e desvinculadas da realidade sociocultural (hortas, jardins, seleção de lixo, aproveitamento de matérias recicláveis) em algumas aulas, principalmente na Semana do Meio Ambiente, ele já estará trabalhando educação ambiental e "fazendo a sua parte", como "manda o figurino".

A dispedagogia ambiental faz com que a educação ambiental perca suas finalidades, descaracterizando-se enquanto processo educativo permanente e contínuo, uma vez que se torna acrítica e reprodutora, deixando de lado tanto os fundamentos da pedagogia que busca responder aos desafios de nosso tempo, como os fundamentos da própria educação ambiental, que visa fomentar novas atitudes críticas e éticas nos indivíduos e na coletividade.

A conseqüência clara da dispedagogia ambiental é o que Waldman (PINSKY; PINSKY, 2003, p. 548) chama de deseducação ambiental. O autor enfatiza que a deseducação ambiental é evidente em vários aspectos de nosso cotidiano, já que nossos modelos culturais, quase sempre desdobramentos oriundos de países desenvolvidos, como se fossem autênticos referenciais de percepção, colonizam cada um de nós. O autor acredita que, em função disso, temos desde o imaginário infantil, um modelo de natureza baseado em ecossistemas e em seres vivos que não existem em nosso país. Ao desconsiderar todo um conjunto nacional mais próximo e, comparativamente, muito mais rico em lendas, representações e mesmo variedade, desconsideram-se também as relações deste conjunto com o modelo de desenvolvimento vigente.

Essa dispedagogia ambiental, embasada em práticas e recursos pedagógicos que reforçam a cultura da inocência (GIROUx, 2003) e a docilização em vez da politização, gera todo um conjunto de ações que conduzem à deseducação ambiental, comprovada por práticas consumistas e posturas socioambientais equivocadas, observadas em nossa sociedade, lamentavelmente vivenciadas por indivíduos que passaram pela escola. 


\section{Retomando a trajetória: articulações da educação ambiental com desenvolvimento, cidadania e justiça ambiental}

O fato mencionado de que professores trabalhem a educação ambiental preferencialmente com o viés ecológico, pode advir de dois fatores: o primeiro, já ressaltado neste trabalho, diz respeito à questão da formação do professor, uma vez que esta se desenvolve, no contexto atual, com um forte componente fragmentador, o que direciona uma prática também fragmentada, gerando a não valorização da educação como processo integral; o segundo, um resquício histórico, para o qual a questão da educação ambiental se configura com o mesmo tratamento dado pelos movimentos ambientalistas - de forma puramente preservacionista. Esta visão preservacionista se encontra presente na maioria dos livros didáticos, nas obras que dissertam sobre o tema e mesmo na legislação brasileira - Política Nacional de Meio Ambiente (Lei 6.938/81), a Constituição Federal, a Política Nacional de Educação Ambiental (Lei 9.795/99), entre outras.

A necessidade de compreender educação ambiental como um processo educativo amplo e permanente, necessário à formação do cidadão, torna-se um fator essencial tanto para a qualidade da educação, como para o direcionamento da formação do docente, pois a abordagem disciplinar não abrange a complexidade do processo educativo. A educação não pode ser vista como uma atividade redentora e nem tampouco uma forma de ascensão social. Como defende Gimeno Sacristán (2002, p. 18), a educação é um "projeto reflexivamente dirigido, como um instrumento para construir [...] pilares da humanização".

Este projeto reflexivo emerge da experiência e da sabedoria que permeiam as relações homem-cultura de forma a construir um sujeito/cidadão, autônomo e independente, mas, ao mesmo tempo, sociocultural e, por isso interdependente. Logo, o professor é chamado a participar não apenas de um projeto permeado de percepção de fatos, situações e posturas, mas, antes de tudo, a estruturar-se no espaço da educação para assim, assumir criticamente sua capacidade reflexiva e ser capaz de identificar os mecanismos de ocultação e dominação que garantem a existência de dominantes e, conseqüentemente, de dominados.

Ao perceber a educação como um direito da cidadania, é pertinente também considerar que esta pode contribuir para a conquista desse princípio ao incentivar discussões, participação, reivindicações, assim como ações concretas e engajamento responsável e ético de cada um, enquanto sujeito e enquanto coletividade. 
GOUVÊA, G. R. R. Rumos da formação de professores para a...

Na condução deste processo, o professor apresenta-se como figurachave, desde que se reconheça como agente de transformação; e agente em transformação num ciclo dialético, visto por Mata (1999, p. 56), capaz de confundir-se com a formação/exercício de cidadania, compreendendo uma outra forma de encarar a relação homem/natureza e de identificar as condições de existência que alienam e excluem, garantindo aos educandos a mobilização e a construção de relações indispensáveis à compreensão da vida cotidiana e da sobrevivência.

A apropriação da dimensão evolutiva do princípio de cidadania é essencial à compreensão da educação ambiental como processo; este também compreendido como construção permanente, pois a construção tanto da educação como da cidadania ultrapassam o muro e a própria vida escolar. Assim, estar alerta às relações entre educação e cidadania é estar consciente da formação do que Alencar (2000, p. 443) chama de "sujeitos do presente e agentes do futuro", possibilitando a renovação de processos, conteúdos, sentidos e significados da educação.

Como o princípio de cidadania está intimamente ligado à educação, por conseguinte, também o está à educação ambiental, ao considerar esta última como uma dimensão do processo educativo. Assim, outros conceitos estão diretamente ligados a este processo. Elege-se, neste trabalho, o conceito de justiça ambiental, uma vez que também se apresenta como um conceito amplo e complexo, alcançando dimensões diversas.

O conceito de justiça ambiental, formulado por Porto (2004, p. 122), baseia-se na Declaração de Princípios da Rede Brasileira de Justiça Ambiental:

Justiça ambiental é entendida por um conjunto de princípios e práticas que asseguram que nenhum grupo social, seja ele étnico, racial, de classe ou gênero, "suporte uma parcela desproporcional das conseqüências ambientais negativas de operações econômicas, decisões políticas e de programas federais, estaduais, locais, assim como da ausência ou omissão de tais políticas”, assegurando assim tanto o acesso justo e eqüitativo aos recursos ambientais do país, quanto o acesso amplo às informações relevantes que lhes dizem respeito e favorecendo a constituição de movimentos e sujeitos coletivos na construção de modelos alternativos e democráticos em desenvolvimento. 
A inserção de princípios e práticas sociocríticas no processo de educação ambiental também tem por objetivo assegurar a promoção da justiça ambiental.

Assim, refletir a questão da cidadania e da justiça ambiental como princípios a serem perseguidos pelo processo educativo, tanto servem para compreensão dos paradigmas de desenvolvimento, como para construir os pilares da humanização, permeados pela cultura, como forma de combater a alienação e a despolitização largamente disseminadas em nossa sociedade.

\section{Mapeando os rumos: revelações de campo}

As políticas de educação ambiental que estão sendo construídas no Brasil, ainda estão longe de suscitar transformações estruturais. Leis e Viola et al. (1998, p. 136) reforçam esta posição ao lembrar que, embora as políticas públicas ambientais venham se consolidando, o poder político continua impotente em sua função de fazer cumprir a legislação vigente. Desta forma, Leff (2001, p. 256) julga necessário uma ruptura paradigmática para que o desenvolvimento de políticas de educação ambiental converta-se em processos estratégicos, com o propósito de orientar valores e comportamentos socioambientais, capazes de transcender o discurso puramente ecologizante, bem como fomentar

\footnotetext{
novas atitudes nos sujeitos sociais e novos critérios de tomada de decisões dos governos [...], de forma a educar para a formação de um pensamento crítico, criativo e prospectivo, capaz de analisar as complexas relações entre processos naturais e sociais, para atuar no ambiente com uma perspectiva global mas, diferenciada pelas condições naturais e culturais que o definem.
}

Nesse percurso foi inspirado o presente estudo, então motivado pela busca da construção da cidadania, na manutenção do diálogo, na contextualização, na problematização e na construção de saberes. Mesmo reconhecendo a importância da educação informal, optou-se por enfatizar a educação formal e, nela, basicamente, a questão da formação de professores. Destarte, o pressuposto de 
Freire (2003, p. 98) de que a educação é uma forma de intervenção no mundo, uma intervenção participativa, contextualizada, política e ética parece ser um rumo a ser seguido na implantação/desenvolvimento de um processo de educação ambiental direcionado à compreensão e à articulação dos aspectos políticos, econômicos, sociais, culturais ao aspecto ambiental.

A presente pesquisa se caracteriza como um estudo de caso (YIN, 2001), desenvolvido em duas instituições de ensino superior, localizadas em cidades e estados diferentes (Lorena/SP; Barra Mansa/RJ), com 126 professorandos dos cursos normal superior e pedagogia. A escolha se deu em função de ambas serem as primeiras instituições de ensino superior de suas cidades, bem como pela participação significativa na formação de inúmeros professores que atuam, principalmente, em escolas do Vale do Paraíba.

Como Yin (2001) preconiza, um estudo de caso deve apresentar variadas evidências, a saber: documentação: estudos da matriz curricular e dos projetos pedagógicos dos cursos; pesquisa histórica sobre cada uma das instituições de ensino onde a pesquisa foi desenvolvida; registros em arquivos: análise dos planos de curso, diários de classe e algumas anotações de aulas dos professores dos cursos; mapas regionais; dados censitários entre 1980 e 2000; entrevistas: relatos e depoimentos dos professorandos no desenvolvimento das atividades propostas; observações diretas: identificação e análise local dos problemas socioambientais das regiões; observação, in loco, da participação dos grupos nas atividades desenvolvidas; observação participante: organização de oficinas e atividades que foram desenvolvidas com as turmas; mediação nas discussões, debates e avaliações dos textos trabalhados, oficinas e atividades desenvolvidas; artefatos físicos: fotos das atividades; textos variados.

A análise dos dados e das evidências extraídas ao longo da realização do estudo de caso receberam tratamento quantitativo e qualitativo, de acordo com as especificidades de cada um. Destaca-se, neste trabalho, a organização de seis oficinas, que no conjunto receberam a nomenclatura de "Treinando o Olhar" e, que com o decorrer do trabalho, tornou-se possível supor que as oficinas tenham servido para aquilo que Vieira $(1998$, p. 69) chama de instrumento essencial à deflagração de um processo endógeno de identificação de problemas e necessidades, iniciando-se, então, não somente o processo de participação autêntica, valorizando os diversos enfoques apresentados, mas, sobretudo, a reconstrução do saber não apenas científico mas, principalmente, o saber que traz novas (re)significações sociais e novos posicionamentos éticos e práticos diante dos problemas levantados - a base do saber ambiental (cf. LEFF, 2001). Assim, a partir dessas premissas, as oficinas foram organizadas e vivenciadas pelo grupo, acreditando que, como Freire defendia (2000, p. 67), "se a educação sozinha não transforma a sociedade, sem ela tampouco a 
sociedade muda".

Na Oficina 1 a capacidade de observação de cada professorando foi explorada no ambiente sócio-histórico de cada componente do grupo, por outro lado, as Oficinas 2, 3, 4 e 5 tiveram o objetivo principal de oferecer aos professorandos um referencial teórico sobre a questão da educação ambiental, além do referencial aplicável sobre o que preciso saber, o que fazer e como se pode desenvolver um trabalho de educação ambiental em sua vida profissional, tendo em vista que o exemplo é uma poderosa forma para transformar e reestruturar a prática educativa, além de, paralelamente, estabelecer uma permanente reflexão crítica do recurso escolhido. A Oficina 6 foi considerada uma oficina-síntese de avaliação, pois possibilitou o resgate dos conceitos trabalhados anteriormente.

Os dados quantitativos desta parte do trabalho foram levantados sob forma de escalas de satisfação do tipo Likert, apresentadas ao final de cada oficina. Cada ficha também apresentava espaço para críticas e observações livres, resguardados, contudo, o sigilo do grupo/aluno, como uma tentativa de garantir a liberdade de expressão.

Os depoimentos e reações considerados como relevantes foram anotados e transcritos como elementos constitutivos da análise qualitativa. Apresenta-se abaixo, as oficinas desenvolvidas:

Oficina 1 - Conhecendo a sua cidade: consistiu em registrar através de fotos, filmes ou desenhos os principais problemas socioambientais da cidade ou bairro escolhido para o desenvolvimento do trabalho, determinando causas, conseqüências, soluções possíveis e responsabilidades individuais e coletivas para a resolução dos mesmos. A oficina culminou com a organização de um painel fotográfico amostral no pátio das instituições e debates sobre os temas envolvidos.

Oficina 2 - Histórias infantis: procurou-se identificar o tratamento das questões socioambientais presentes na arte literária brasileira. A partir desta oficina, os professorando tiveram a oportunidade de escolher, ler, discutir e organizar estratégias pedagógicas para apresentarem as histórias escolhidas (e os demais recursos utilizados nas outras oficinas) a seus alunos, identificado valores e posicionamento éticos necessários para compreender os problemas socioambientais.

Oficina 3 - Música: esta oficina permitiu a leitura crítica de letras de música popular brasileira, identificando letras que fizessem alusão às questões socioambientais, situando-as ao contexto histórico específico ocorrido no período em que as letras foram escritas.

Oficina 4 - Histórias em quadrinhos/charges: com um direcionamento 
GOUVÊA, G. R. R. Rumos da formação de professores para a...

semelhante ao da de oficina de histórias infantis, a oficina permitiu a leitura de histórias em quadrinhos e interpretações de charges variadas.

Oficina 5 - Vídeos: esta permitiu a análise da visão de mundo e dos processos sócio-históricos subjacentes às questões socioambientais, propagadas pela mídia.

Oficina 6 - Árvore do conhecimento ${ }^{1}$ : consistiu em apresentar registros escritos em mural coletivo, de palavras/conceitos/problemas ambientais, no qual cada grupo era chamado a descobrir interligações entre eles.

Todas as oficinas eram desenvolvidas em grupos e precedidas de referenciais bibliográficos referentes às questões sobre formação de professores, educação ambiental, utilização didático-pedagógica de cada um dos recursos escolhidos, entre outros.

\section{Encerrando a caminhada? Considerações finais}

A presente pesquisa visou ao desafio de se repensar a educação ambiental e sua forma de inserção na escola e nos cursos de formação de professores. Mais do que apresentar técnicas que possam ser desenvolvidas em sala de aula, como suporte técnico a professores em formação, buscou-se fazer reflexões para inserir a questão ambiental no contexto da EDUCAÇ̃̃o.

Ao assumir a necessidade de difundir a tendência transformadora do intelectual transformador como uma das formas de alterar rotinas preestabelecidas, de enfrentar os problemas e desafios existentes na escola e no processo educativo, buscou-se valorizar, nos professorandos, a reflexão permanente das funções sociais à prática pedagógica de cada um, observando-se a participação das aulas, o desenvolvimento dos trabalhos sugeridos e o engajamento/envolvimento de cada um nos problemas de seu ambiente de vida e trabalho. Ao oferecer aos professorandos oportunidade de perceber a sua realidade nos aspectos social, cultural, econômico, ambiental e as inter-relações existentes entre eles, deu-se a contribuição à percepção de que, a partir da realidade co-

\footnotetext{
${ }^{1} \mathrm{O}$ nome desta oficina originou-se após a mesma ter sido vivenciada e executada por dois motivos: o primeiro a partir da representação que a maioria dos grupos utilizou para representar as interligações entre os conceitos, quase sempre em forma de árvores e, o segundo, a partir da leitura do livro “Árvore do conhecimento”, de Humberto Maturana.
} 
tidiana, podem-se ultrapassar os limites impostos pelas diretrizes brasileiras no que se refere à educação, convergindo para a superação da dispedagogia e da deseducação ambiental.

A superação da dispedagogia e da deseducação ambiental será possível a partir da construção de uma pedagogia e um saber ambiental, embasados na perspectiva da transformação social do educador, pois assim será possível um trabalho educativo voltado à relação dialética entre homem $\leftrightarrow$ sociedade $\leftrightarrow$ ambiente, orientados pelos princípios da ética, justiça e cidadania. Percorrer o ciclo ação $\leftrightarrow$ reflexão $\leftrightarrow$ ação permitirá aos educadores em formação, a percepção de que enquanto profissionais, todos estão em permanente transformação, ao mesmo tempo em que possibilitam a transformação de outros.

Nesse sentido, faz-se necessário compreender a importância de resgatar o princípio de cidadania, associado ao objeto do meio ambiente, tanto para os educandos, como para os educadores. Este é um outro desafio: tornar alunos e professores sujeitos participantes da história, capazes de não só conquistar um espaço para desenvolver educação ambiental, enquanto processo educativo, como também desvendar os sentidos da democracia, do desenvolvimento, da justiça. Talvez aqui se insere a verdadeira função da educação ambiental: fazer perceber que para além do trabalho em uma lógica ecológica, é fundamental tecer um "fio que una as pedras" para que a educação ambiental seja, permanentemente compreendida e trabalhada, em todo o processo educativo, o que implica em revisão de currículos e seus desdobramentos lógicos e ideológicos, bem como do papel da educação e dos atores que dela participam.

Embora consciente de ter trabalhado com um universo de pesquisa pequeno, ele tornou-se significativo no contexto regional, pois a amostra foi constituída com professorandos de vários municípios da região do Vale do Paraíba e todos tiveram oportunidade de demonstrar em suas ações, ao longo do processo, a possibilidade de (re)criar e (re)fazer uso dos sentidos, dos sentimentos, da imaginação, da memória e da inteligência para agir sobre a realidade, transformá-la, adaptá-la a suas necessidades e recursos (RIOs, 2001, p. 84).

A partir da análise dos dados e das fontes de evidência utilizadas no percurso deste estudo de caso, há evidências de que:

- No que se refere à documentação: o estudo exploratório, iniciado em 2001, contemplou a análise dos projetos pedagógicos e das matrizes curriculares dos cursos, e revelou que estes não enfatizavam a questão da educação ambiental no contexto da educação. Os resultados deste estudo originaram o projeto desenvolvido, com a concordância dos coordenadores de curso de ambas as instituições. Mesmo durante a 
GOUVÊA, G. R. R. Rumos da formação de professores para a...

pesquisa, deve-se ressaltar que os projetos pedagógicos dos cursos das duas instituições foram alterados e a dimensão socioambiental foi introduzida no processo de formação dos profissionais (pedagogos e professores) como responsabilidade de todos que atuam no processo educativo;

- $\quad$ No que se refere à observação dos registros em arquivos: a pesquisa se fez com o auxílio de diversos profissionais (professores das diversas disciplinas, funcionários das secretarias das instituições, funcionários do IBGE), que disponibilizaram os dados e se dispuseram a debater o assunto, sendo que vários colegas, professores, já direcionavam seus programas com discussão de temas que auxiliam na formação do intelectual público e reflexivo, como: globalização, neoliberalismo, cidadania, democracia, ética, cultura, entre tantos outros, necessários não apenas à formação do saber e da pedagogia ambiental, mas principalmente ao combate da dispedagogia e da deseducação ambiental.

- No que se refere às entrevistas: os relatos e depoimentos dos professorandos (alguns inclusos no trabalho original), demonstram claramente que estes perceberam a diferença entre trabalhar educação em uma perspectiva socioambiental e a educação como atividade reprodutora.

- $\quad$ No que se refere às observações diretas: a identificação dos tipos de problemas apresentados pelos grupos demonstra que o aspecto sociopolitico-econômico do processo de educação ambiental foi plenamente alcançado, assim como a capacidade de refletir sobre suas causas, conseqüências e possíveis soluções.

- $\quad$ No que se refere à observação participante: no processo de desenvolvimento das oficinas, percebeu-se o envolvimento total dos professorandos, não apenas realizando o que foi solicitado, mas também trazendo materiais novos e relatos de ações desenvolvidas em sua própria escola/bairro. Este aspecto revelou-se tangível, apesar da dificuldade inicial em apreender que o trabalho de educação ambiental envolvia muitos aspectos, e não somente o aspecto natural/ecológico. Também foi relevante o auxílio de outros professores dos cursos. Nesse sentido, a escolha consciente dos textos e o direcionamento político e filosófico de seus autores auxiliaram sobremaneira na apreensão de que o trabalho de Educação Ambiental se insere no desenvolvimento do processo educativo. Deve-se ressaltar que este aspecto foi plenamente atendido em função da alteração, não da 
matriz curricular dos cursos, mas do direcionamento do projeto pedagógico de cada um deles e do envolvimento de todo o colegiado de professores, que ao compreender a proposta, abraçaram-na como sendo essencial na formação do profissional.

- No que se refere aos artefatos físicos auxiliares: parte deles foi cedida pelos professorandos nos trabalhos das oficinas. Esses artefatos (fotos) serviram, também, como processo avaliativo da proposta e mesmo da mudança conceitual e da postura de cada aluno no que se refere aos problemas ambientais. Os textos foram escolhidos com a certeza de que a reflexão se faz não apenas com conceitos, mas com todo o aparato de juízo, categorias, raciocínio, visão ética e política, conceitos cuja construção deve ocorrer uma a uma, interna, individual e coletivamente. A escolha e a discussão destes textos permitiram compreender que o diálogo e a participação são condições condição sine qua non para a formação de professores e de cidadãos.

Ousa-se, assim, afirmar que o processo de educação ambiental, no âmbito formal, concentra-se no docente sócio-histórico, que atua na educação como processo contínuo e político, que compreende a necessidade de experimentar e criar práticas pedagógicas significativas, trazendo em seu escopo o desafio de sermos eternos “do-discentes” (FREIRE, 2003). Trata-se de uma tarefa complexa, imensa e ubíqua, mas não se pode sucumbir às desesperanças; antes investir na utopia do possível, para então planejar e iniciar um caminho em construção.

\section{REFERÊNCIAS}

ALENCAR, C. Terra dos sem-cidadania. In: AZEVEDO, J.; GENTILI, P. et al. (Orgs.). Utopia e democracia na educação cidadã. Porto Alegre: Universidade/UFRGS/Secretaria Municipal de Educação, 2000.

BOFF, L. A águia e a galinha: uma metáfora da condição humana. 29. ed. Petrópolis: Vozes.1999.

BRASIL. Constituição da República Federativa do Brasil. Brasília: Senado, 1988.

. Lei n. 6.938. Política Nacional de Meio Ambiente. Diário Oficial da República Federativa do Brasil, Brasília, 2 set. 1981.

Ministério do Meio Ambiente (MMA). Lei n. 9.597. Política Nacional de 
GOUVÊA, G. R. R. Rumos da formação de professores para a...

Educação Ambiental. Diário Oficial da República Federativa do Brasil, Brasília, 28 abr. 1999.

CARVALHO, V. S. de. Educação ambiental e desenvolvimento comunitário. Rio de Janeiro: Wak, 2002.

CASTRO, R.; LAYRARGUES, P.; LOUREIRO, C. (Orgs.). Educação ambiental: repensando o espaço da cidadania. São Paulo: Cortez, 2002.

FONSECA, V. Introdução às dificuldades de aprendizagem. 2. ed. Porto Alegre: Artes Médicas, 1995.

FREIRE, P. Pedagogia da autonomia: saberes necessários à prática educativa. 27. ed. São Paulo: Paz e Terra, 2003.

Pedagogia da indignação: carta pedagógica e outros escritos. São Paulo: Unesp, 2000.

GIMENO, S. J. Educar e conviver na cultura global: as exigências da cidadania. Porto Alegre: Artes Médicas, 2002.

GIROUX, H. Atos impuros. Porto Alegre: Artes Médicas, 2003.

. Os professores como intelectuais. Rumo a uma pedagogia crítica da aprendizagem. Porto Alegre: Artes Médicas, 1997.

LEFF, E. (Org.). A complexidade ambiental. São Paulo: Cortez, 2003.

. Epistemologia ambiental. 2. ed. São Paulo: Cortez, 2002.

Saber ambiental: sustentabilidade, racionalidade, complexidade, poder. Petrópolis: Vozes, 2001.

LEIS, H.; VIOLA, E. et al. Meio ambiente, desenvolvimento e cidadania: desafios para as ciências sociais. 2. ed. São Paulo: Cortez, 1998.

MATA, S.; GAVAZZA, S. et al. (Orgs.). Educação ambiental: projetivas do século. Rio de Janeiro: Terceiro Milênio, 1999.

MATURANA, H.; VARELA, F. A árvore do conhecimento. Campinas: Psy, 1995.

PORTO, M. F. de S. Saúde pública e (in)justiça ambiental no Brasil. In: ACSELRAD, H.; HERCULANO, S.; PÁDUA, J. A. Justiça ambiental e cidadania. Rio de Janeiro: Relune Dumará, 2004.

RIOS, T. Compreender e ensinar. Por uma docência da melhor qualidade. São Paulo: Cortez, 2001.

VIEIRA, P. F. Meio ambiente, desenvolvimento e planejamento. In: LEIS, H. et al. Meio ambiente, desenvolvimento e cidadania: desafios para as ciências sociais. 2. ed. São Paulo: Cortez, 1998.

WALDMAN, M. Natureza e sociedade como espaço de cidadania. In: PINSKY, J.; 
GOUVÊA, G. R. R. Rumos da formação de professores para a...

PINSKY, C. História da cidadania. São Paulo: Contexto, 2003.

YIN, R. Estudo de caso: planejamento e métodos. 2. ed. Porto Alegre: Bookman, 2001.

Texto recebido em 23 set. 2005

Texto aprovado em 11 nov. 2005 